\title{
Doctoring the drinkers
}

Patients should be informed that records may be used in this way and given the opportunity to opt-out.

When inviting patients to take part in a study, the GP should screen the proposed list before any contact. The invitation should come from the GP, signed, and on practiceheaded paper. It is appropriate for researchers to provide administrative support. It must be made clear that the patient's decision will not affect the quality of their care. The practice retains ultimate accountability for the process.

Informed consent. The process for seeking consent, once the researcher or GP is working directly with the patient, is well established. ${ }^{6,7}$ It should be clear that participation is voluntary, and that participants have the right to withdraw at any time. Consent (or dissent) should be recorded in the patient record, unless a patient specifies otherwise.

\section{Conclusion}

The best practice guidance described in this document is a first step in a process to ensure that patients and GPs have confidence in the processes used to access patient information, and to enable everyone to benefit from the significant research potential of patient records.

\section{Nigel Mathers, Nicola MR Perrin and Graham CM Watt}

\section{(C) Wellcome Trust}

Perrin NMR, Mathers N, Watt GCM. Towards a consensus on best practice: use of patient records for research in general practice. London: Wellcome Trust, 2008.

Available at: www.wellcome.ac.uk/GPrecords

\section{REFERENCES}

1. Academy of Medical Sciences. Personal data for public good using health information in medical research. London: AMS 2006.

2. Thomas R, Walport M. Data sharing review. 2008. http:// www.justice.gov.uk/docs/data-sharing-review.pdf (accessed 13 Oct 2008).

3. Medical Research Council. The use of personal health information in medical research. London: MRC, 2007.

4. RCGP. Research Ready: self-accreditation. http://www.rcgp. org.uk/clinical_and_research/circ/research/primary_care_res earch_team_ass/research_ready.aspx (accessed 13 Oct 2008).

5. General Medical Council. Research: the role and responsibilities of doctors. Manchester: GMC, 2002.

6. General Medical Council. Consent: patients and doctors making decisions together. 2008. http://www.gmc-uk.org/ guidance/ethical_guidance consent_guidance/index.asp (accessed 13 Oct 2008)

7. Medical Research Council. Personal information in medical research. 2008. http://www.mrc.ac.uk/Utilities/Document record/index.htm?d=MRC002452 (accessed 13 Oct 2008).

DOI: 10.3399/bjgp08X342750
'Your GP is the first place to turn if you are concerned about your drinking' - this was the concluding advice of a recent eightpage newspaper supplement devoted to 'Britain's harmful relationship with alcohol'.' Once regarded as a manifestation of moral turpitude, excessive drinking has been redefined as a medical condition and doctors have taken the place of evangelical ministers at the head of the modern temperance crusade. The fact that doctors come second only to publicans in terms of occupational risk of death from alcoholinduced cirrhosis of the liver does not seem to have diminished medical authority in this area. ${ }^{2}$

The ascendancy of GPs in dealing with alcohol problems is based on claims for the effectiveness of 'brief interventions' in general practice. This means doctors giving patients a quick (but of course empathetic, supportive, and non-judgmental) lecture on the adverse health consequences of alcohol and advising them to cut back. ${ }^{3}$ But close scrutiny of these studies reveals that their high success rates are achieved by excluding patients who are alcohol dependent (including only those deemed to have 'hazardous' or 'harmful' levels of drinking), by following up for a short period (usually less than 12 months), and by defining success in terms of a reduction in total consumption or episodes of binge drinking (rather than achieving abstinence).

A systematic review noted that 'only one in four patients who screen positive for excessive drinking qualify for brief intervention after further assessment' and that 'only two to three patients per thousand screened will benefit from the laborious activities involved in screening'. ${ }^{4}$ Noting the 'questionable' validity of many of the trials of screening-based brief interventions, the authors concluded that 'screening in general practice does not seem to be an effective precursor to brief interventions targeting excessive alcohol use'. These observations provoked a predictable angry backlash from the public health zealots and, equally predictably, have not deterred the introduction of programmes of screening and brief intervention in general practice, already a feature of incentivised local 'enhanced services' and soon to be incorporated in the Quality and Outcomes Framework. It seems that if doctors suggest to patients who are drinking over the odds that they should consider cutting back, a few do, for a while, before resuming their old habits. $A$ desperate resort to old-fashioned medical paternalism? Yes. A solution to 'Britain's harmful relationship with alcohol'? No.

An instinctive recognition of the ineffectiveness of medical intervention and indeed of medical treatment - for problems of excessive alcohol consumption has lead prominent doctors and medical organisations into campaigning for prohibitionist measures. No newspaper or television feature on alcohol is now complete without a leading liver specialist, psychiatrist, or GP demanding more regulations and restrictions on the sale of alcohol, calls for curtailing advertising and promotional activities, proposals for raising prices, and for tougher policing of licensing laws. But if doctors cannot treat alcoholism in their surgeries, why should anybody accept their proposals in the sphere of social policy where they have no expertise whatsoever? From the gin panic in England in the 1730s to the Volstead Act in the US in the 1920s, there is abundant historical evidence that such measures are likely to be counterproductive. ${ }^{5}$

The notion that doctors can treat the nation's alcohol problem is a delusion that is convenient for the medical profession and for politicians eager to respond to the latest moral panic. But it marks an evasion of the real issues of personal and social demoralisation that are expressed in selfdestructive patterns of alcohol consumption, which are not susceptible to medical - or political - quick-fixes.

\section{REFERENCES}

1. The Guardian: Alcohol and us. http://www.guardian. co.uk/theguardian/2008/sep/10/alcoholandus/alcoho landus (accessed 9 Oct 2008)

2. Plant M, Cameron D, (eds). The Alcohol Report. London: Free Association Books Ltd, 2000.

3. Scottish Intercollegiate Guidelines Network.The management of harmful drinking and alcohol dependency in primary care. A national clinical guideline (74). Edinburgh: SIGN, 2003.

4. Beich A, Thorsen T, Rollnick S. Screening in brief intervention trials targeting excessive drinkers in general practice: systematic review and metaanalysis. BMJ 2003; 327: 536-542.

5. Dillon P. Gin: the much-lamented death of Madam Geneva. Boston: Justin Charles \& Co., 2002.

This is a version of an article that was published in the Times on 6 October 2008:

http://www.timesonline.co.uk/tol/comment/spe cials/article4893339.ece

DOI: 10.3399/bjgp08X342769 